\title{
Treatment of Polycystic Ovary Syndrome-Related Infertility Using a Combination of Compound Xuanju Capsules and Hormone Therapy: A Meta-Analysis
}

\section{Qianwen Ma}

Zhenjiang hospital of TCM

Yong Tan ( $\nabla$ nzyszy@163.com )

Nanjing University of Chinese Medicine

\section{Research}

Keywords: compound Xuanju capsules, hormone, polycystic ovary syndrome, infertility, meta analysis

Posted Date: November 30th, 2021

DOI: https://doi.org/10.21203/rs.3.rs-1038721/v1

License: (9) This work is licensed under a Creative Commons Attribution 4.0 International License. Read Full License 


\section{Abstract \\ Objective}

To compare the therapeutic effects of compound Xuanju capsules combined with hormone therapy versus hormone therapy alone on polycystic ovary syndrome (PCOS)-related infertility using a meta-analysis.

\section{Methods}

Electronic databases including PubMed, The Cochrane Library, Web of science, Chinese Biomedical Literature Database (CBM), China National Knowledge Infrastructure (CNKI), Wanfang Data, and VIP database were manually searched. The quality of included studies was evaluated based on the Cochrane systematic review standards, and the valid data were extracted for meta-analysis using Revman 5.3 software.

\section{Results}

A total of 14 randomized controlled trials accounting for 1249 patients were included. Meta-analysis showed that patients in the compound Xuanju capsule + hormone therapy group had higher estradiol levels and overall rates of effective treatment than those in the hormone therapy alone group. Moreover, they also exhibited lower levels of luteinizing hormone and follicle-stimulating hormone as well as lower Kupperman scores than the hormone therapy alone group.

\section{Conclusions}

The combination of compound Xuanju capsules and hormone therapy is more effective than hormone therapy alone in the treatment of PCOS-related infertility. However, the quality of current studies is low, and high-quality clinical trials are warranted.

\section{Introduction}

In today's modern society, work-related stress has substantially increased, resulting in rising rates of female reproductive disorders such as polycystic ovary syndrome (PCOS), infertility, premature ovarian failure, and irregular menstruation. PCOS is a common condition associated with multimorbidity in women of reproductive age and is often accompanied by insulin resistance and obesity ${ }^{[1-5]}$. It is characterized by ovulatory disorders, hyperandrogenism, and polycystic ovarian changes, and its primary clinical manifestations are menstrual abnormalities, infertility, and acne. Infertility refers to a condition wherein women fail to achieve pregnancy after 1 year or more of regular unprotected sexual intercourse. In PCOS, ovulatory disorder is an important inducer of infertility. Currently, western allopathybased treatments for PCOS-related infertility use anti-androgens, aiming to regulate the menstrual cycle and induce ovulation. Hormone therapy with agents such as clomiphene, letrozole, tamoxifen, tripurelin, and progesterone is often the preferred modality for PCOS treatmen ${ }^{\mathrm{t}[6-10]}$

Although hormone therapy can improve hormone levels and the ovulation rate to a certain extent, it can cause several adverse effects and is less effective in improving clinical symptoms. Over the past few decades, the advantages of traditional Chinese medicine - which is gradually being applied for the treatment of PCOS-related infertility - are being highlighted. Some researchers have suggested that hormonal therapy combined with traditional Chinese medicine can improve therapeutic effects and pregnancy rates while exerting low toxicity and showing a good safety profile. Therefore, in the present study, we aimed to conduct a meta-analysis of the current clinical findings related to the effectiveness of compound Xuanju capsules combined with hormone therapy for the treatment of PCOS-related infertility in order to elucidate whether this combination provides more advantages than hormone therapy alone.

\section{Materials And Methods}

\subsection{Inclusion and exclusion criteria}

All randomized controlled trials (RCTs) examining the effect of compound Xuanju capsules combined with hormone therapy for treating PCOS-related infertility were retrieved. Duplicate publications and studies containing erroneous, incomplete, or unavailable data were 
excluded. In addition, studies wherein compound Xuanju capsules + hormone therapy was not adopted in the treatment arm and those wherein hormone therapy alone was not adopted in the control arm were excluded.

\subsection{Intervention and outcome measures}

The treatment arm included compound Xuanju capsules + hormone therapy, whereas the control arm included hormone therapy alone. The outcome measures were the overall rate of effective treatment, luteinizing hormone (LH) and follicle-stimulating hormone (FSH) levels, the LH/FSH ratio, estradiol $\left(E_{2}\right)$ levels, testosterone $(T)$ levels, overall rate of effective Chinese medicine-based treatment, ovarian volume, ovulation rate, pregnancy rate, basal body temperature (BBT), antral follicle count, endometrial thickness, maximum follicle diameter, follicle count, and hepatocyte growth factor (HGF) and vascular endothelial growth factor (VEGF) levels.

\subsection{Search strategy}

Electronic databases including PubMed, The Cochrane Library, Web of science, Chinese Biomedical Literature Database (CBM), China National Knowledge Infrastructure (CNKI), Wanfang Data, and the VIP database were manually searched. The keywords used were as follows: "compound Xuanju capsule," "Xuanju," "compound Xuanju," "hormone," "western medicine," "E $\mathrm{E}_{2}$," "progesterone," "clomiphene," "letrozole," "tamoxifen," "tripurelin," "PCOS," "sterility," and "infertility," etc. There were no publication date or journal restrictions applied.

\subsection{Data extraction and quality evaluation}

Two evaluators read the title and abstract independently. After excluding studies that clearly did not meet the inclusion criteria, they reviewed the full text to determine whether the studies should be included. Any disagreements were resolved via discussions. Based on the quality evaluation standards described in the Cochrane Handbook for Systematic Reviews of Interventions, the following aspects were evaluated $^{[11]}$ : (1) What random sequence generation was adopted?; (2) Was allocation concealment adopted?; (3) Was blinding adopted?; (4) Was there any incomplete outcome data bias?; (5) Was there selection bias?; and (6) Was there any other bias?

\subsection{Statistical analyses}

All the statistical analyses were performed using Review Manager Version 5.3 provided by the Cochrane Collaboration Network. Chisquare $\left(\chi^{2}\right)$ analysis was performed to evaluate heterogeneity. At $2<50 \%$, studies were considered to have homogeneity, and the fixed effects model was used for analysis. At $R^{2}>50 \%$, studies were considered to have high heterogeneity, and the random effects model was used. Sensitivity analysis was performed to identify the source of heterogeneity. The efficacy indexes were estimated based on intervals. Enumeration data were expressed as odds ratios (ORs) with 95\% confidence interval (Cls), and measurement data were expressed as weighted mean difference (MDs) and $95 \%$ Cls. The $Z(u)$ test was used to combine statistics, and the probability $(P)$ was obtained according to the $Z(u)$ value. At $P \leq 0.05$, the combined results of multiple studies were considered statistically significant.

\section{Results}

\subsection{Literature search results}

A total of 572 articles were obtained after searching the databases. Of them, 262 were retrieved from CNKI, 56 from Wanfang Data, 253 from VIP, and 1 from Medline. No articles were obtained from the Cochrane Library and Web of Science databases. Of the 572 articles, 550 (including inter-database duplications and irrelevant studies) were excluded, and 22 full texts were obtained. Eight articles that did not meet the inclusion criteria were excluded after full-text review, and 14 RCTs were finally included (figure 1).

\subsection{Methodological quality assessment of included studies}

Fourteen RCTs performed in China, accounting for a total of 1,249 patients with comparable baseline characteristics, were included in this study. The characteristics of the included population are shown in Table 1. As for outcome measures, 6 studies reported the ovulation rate; 11 reported the pregnancy rate; 12 reported FSH levels; 7 reported $\mathrm{E}_{2}$ levels; 12 reported LH levels; 2 reported the LH/FSH ratio; 9 reported T levels; 5 reported endometrial thickness; 6 reported the overall rate of effective treatment; 2 reported the overall rate of effective Chinese medicine-based treatment; 2 reported BBT; 2 reported ovarian volume; 2 reported the maximum follicle diameter; 2 reported follicle count; 2 reported HGF levels; 2 reported VEGF levels; and 2 reported adverse effects. The general characteristics of all included studies are summarized in Table 1. 
Table 1

Basic information of included literatures

\begin{tabular}{|c|c|c|c|c|c|}
\hline Studies & Participants & Treatment group & Control group & $\begin{array}{l}\text { Main } \\
\text { results }\end{array}$ & $\begin{array}{l}\text { Treatment } \\
\text { course }\end{array}$ \\
\hline $\begin{array}{l}\text { Cai DD } \\
2019^{[12]}\end{array}$ & $N=104$ & $\begin{array}{l}\text { Clomiphene+HCG+progesterone+ } \\
\text { compound Xuanju capsules } \\
\mathrm{N}=52\end{array}$ & $\begin{array}{l}\text { Clomiphene+HCG+progesterone } \\
\mathrm{N}=52\end{array}$ & $\begin{array}{l}\text { The } \\
\text { treatment } \\
\text { group } \\
\text { had a } \\
\text { better } \\
\text { effect }\end{array}$ & $\begin{array}{l}\text { One } \\
\text { menstrual } \\
\text { cycle }\end{array}$ \\
\hline $\begin{array}{l}\text { Wang } \\
\text { HY } \\
2016^{[13]}\end{array}$ & $\mathrm{N}=42$ & $\begin{array}{l}\text { Clomiphene+HCG+compound Xuanju } \\
\text { capsules } \\
\mathrm{N}=21\end{array}$ & Clomiphene+HCGN=21 & $\begin{array}{l}\text { The } \\
\text { treatment } \\
\text { group } \\
\text { had a } \\
\text { better } \\
\text { effect }\end{array}$ & $\begin{array}{l}\text { One } \\
\text { menstrual } \\
\text { cycle }\end{array}$ \\
\hline $\begin{array}{l}\text { Yu XR } \\
2021^{[14]}\end{array}$ & $N=86$ & $\begin{array}{l}\text { Clomiphene+progesterone+compound } \\
\text { Xuanju capsules } \\
\mathrm{N}=43\end{array}$ & $\begin{array}{l}\text { Clomiphene+progesterone } \\
\mathrm{N}=39\end{array}$ & $\begin{array}{l}\text { The } \\
\text { treatment } \\
\text { group } \\
\text { had a } \\
\text { better } \\
\text { effect }\end{array}$ & $\begin{array}{l}3 \text { months } \\
\text { or to } \\
\text { pregnancy }\end{array}$ \\
\hline $\begin{array}{l}\text { Sun JL } \\
2009^{[15]}\end{array}$ & $\mathrm{N}=90$ & $\begin{array}{l}\text { Letrozole+HCG+progesterone+compound } \\
\text { Xuanju capsules } \\
\mathrm{N}=30\end{array}$ & $\begin{array}{l}\text { Letrozole+HCG+progesterone } \\
\mathrm{N}=25\end{array}$ & $\begin{array}{l}\text { The } \\
\text { treatment } \\
\text { group } \\
\text { had a } \\
\text { better } \\
\text { effect }\end{array}$ & $\begin{array}{l}3 \\
\text { menstrual } \\
\text { cycles or } \\
\text { to } \\
\text { pregnancy }\end{array}$ \\
\hline $\begin{array}{l}\text { Zhang } \\
\text { JJ } \\
2017^{[16]}\end{array}$ & $\mathrm{N}=78$ & $\begin{array}{l}\text { Clomiphene+HCG+progesterone+ } \\
\text { compound Xuanju capsules } \\
\mathrm{N}=39\end{array}$ & $\begin{array}{l}\text { Clomiphene+HCG+progesterone } \\
\mathrm{N}=39\end{array}$ & $\begin{array}{l}\text { The } \\
\text { treatment } \\
\text { group } \\
\text { had a } \\
\text { better } \\
\text { effect }\end{array}$ & $\begin{array}{l}3 \text { months } \\
\text { or to } \\
\text { pregnancy }\end{array}$ \\
\hline $\begin{array}{l}\text { Huang } \\
\text { XH } \\
2012^{[17]}\end{array}$ & $N=60$ & $\begin{array}{l}\text { Clomiphene+ } \\
\text { compound Xuanju capsules } \\
\mathrm{N}=30\end{array}$ & $\begin{array}{l}\text { Clomiphene } \\
\mathrm{N}=30\end{array}$ & $\begin{array}{l}\text { The } \\
\text { treatment } \\
\text { group } \\
\text { had a } \\
\text { better } \\
\text { effect }\end{array}$ & $\begin{array}{l}3 \text { months } \\
\text { or to } \\
\text { pregnancy }\end{array}$ \\
\hline $\begin{array}{l}\text { Li G } \\
2020^{[18]}\end{array}$ & $\mathrm{N}=88$ & $\begin{array}{l}\text { Triptorelin+compound Xuanju capsules } \\
\mathrm{N}=44\end{array}$ & $\begin{array}{l}\text { Triptorelin } \\
\mathrm{N}=44\end{array}$ & $\begin{array}{l}\text { The } \\
\text { treatment } \\
\text { group } \\
\text { had a } \\
\text { better } \\
\text { effect }\end{array}$ & 4 months \\
\hline $\begin{array}{l}\mathrm{Hu} Y F \\
2017^{[19]}\end{array}$ & $\mathrm{N}=93$ & $\begin{array}{l}\text { Clomiphene+estradiol valerate } \\
+ \text { HCG+progesterone+compound Xuanju } \\
\text { capsules } \\
\mathrm{N}=46\end{array}$ & $\begin{array}{l}\text { Clomiphene+estradiol valerate } \\
+\mathrm{HCG}+\text { progesterone } \\
\mathrm{N}=47\end{array}$ & $\begin{array}{l}\text { The } \\
\text { treatment } \\
\text { group } \\
\text { had a } \\
\text { better } \\
\text { effect }\end{array}$ & $\begin{array}{l}\text { One } \\
\text { menstrual } \\
\text { cycle }\end{array}$ \\
\hline $\begin{array}{l}\text { Hao LN } \\
2018^{[20]}\end{array}$ & $N=150$ & $\begin{array}{l}\text { Letrozole+compound Xuanju capsules } \\
\mathrm{N}=75\end{array}$ & $\begin{array}{l}\text { Letrozole } \\
\mathrm{N}=75\end{array}$ & $\begin{array}{l}\text { The } \\
\text { treatment } \\
\text { group } \\
\text { had a } \\
\text { better } \\
\text { effect }\end{array}$ & $\begin{array}{l}\text { One } \\
\text { menstrual } \\
\text { cycle }\end{array}$ \\
\hline $\begin{array}{l}\text { Chen } \\
\text { ZF } \\
2019^{[21]}\end{array}$ & $N=86$ & $\begin{array}{l}\text { Clomiphene+HCG+progesterone+compound } \\
\text { Xuanju capsules } \\
\mathrm{N}=43\end{array}$ & $\begin{array}{l}\text { Clomiphene+HCG+progesterone } \\
\mathrm{N}=43\end{array}$ & $\begin{array}{l}\text { The } \\
\text { treatment } \\
\text { group } \\
\text { had a } \\
\text { better } \\
\text { effect }\end{array}$ & $\begin{array}{l}3 \text { months } \\
\text { or to } \\
\text { pregnancy }\end{array}$ \\
\hline
\end{tabular}




\begin{tabular}{|c|c|c|c|c|c|}
\hline Studies & Participants & Treatment group & Control group & $\begin{array}{l}\text { Main } \\
\text { results }\end{array}$ & $\begin{array}{l}\text { Treatment } \\
\text { course }\end{array}$ \\
\hline $\begin{array}{l}\text { Yan L } \\
2019^{[22]}\end{array}$ & $N=98$ & $\begin{array}{l}\text { Tamoxifen+compound Xuanju capsules } \\
\mathrm{N}=49\end{array}$ & $\begin{array}{l}\text { Tamoxifen } \\
\mathrm{N}=49\end{array}$ & $\begin{array}{l}\text { The } \\
\text { treatment } \\
\text { group } \\
\text { had a } \\
\text { better } \\
\text { effect }\end{array}$ & $\begin{array}{l}3 \\
\text { menstrual } \\
\text { cycles or } \\
\text { to } \\
\text { pregnancy }\end{array}$ \\
\hline $\begin{array}{l}\text { Ge BB } \\
2021^{[23]}\end{array}$ & $N=108$ & $\begin{array}{l}\text { Clomiphene+progesterone+compound } \\
\text { Xuanju capsules } \\
\mathrm{N}=54\end{array}$ & $\begin{array}{l}\text { Clomiphene+progesterone } \\
\mathrm{N}=54\end{array}$ & $\begin{array}{l}\text { The } \\
\text { treatment } \\
\text { group } \\
\text { had a } \\
\text { better } \\
\text { effect }\end{array}$ & $\begin{array}{l}\text { One } \\
\text { menstrual } \\
\text { cycle }\end{array}$ \\
\hline $\begin{array}{l}\text { Zhou } \\
\text { QM } \\
2020^{[24]}\end{array}$ & $N=96$ & $\begin{array}{l}\text { Tamoxifen+compound Xuanju capsules } \\
\mathrm{N}=48\end{array}$ & $\begin{array}{l}\text { Tamoxifen } \\
\mathrm{N}=48\end{array}$ & $\begin{array}{l}\text { The } \\
\text { treatment } \\
\text { group } \\
\text { had a } \\
\text { better } \\
\text { effect }\end{array}$ & $\begin{array}{l}3 \\
\text { menstrual } \\
\text { cycles or } \\
\text { to } \\
\text { pregnancy }\end{array}$ \\
\hline $\begin{array}{l}\text { Li YY } \\
2021^{[25]}\end{array}$ & $\mathrm{N}=70$ & $\begin{array}{l}\text { Ethinylestradiol-cyproterone } \\
\text { acetate+compound Xuanju capsules } \\
\mathrm{N}=35\end{array}$ & $\begin{array}{l}\text { Ethinylestradiol-cyproterone } \\
\text { acetate } \\
\mathrm{N}=35\end{array}$ & $\begin{array}{l}\text { The } \\
\text { treatment } \\
\text { group } \\
\text { had a } \\
\text { better } \\
\text { effect }\end{array}$ & $\begin{array}{l}16 \text { weeks } \\
\text { or to } \\
\text { pregnancy }\end{array}$ \\
\hline
\end{tabular}

\subsection{Ovulation rate}

No heterogeneity was observed among the 6 studies reporting the ovulation rate $(P=0.86, P=0 \%)$. Meta-analysis with the fixed effects model showed the following: $\mathrm{MD}=2.04,95 \% \mathrm{Cl}[1.46,2.84], \mathrm{Z}=4.18, P<0.0001$. The statistically significant difference between the two groups suggested that the compound Xuanju capsule + hormone therapy group had a higher ovulation rate than the hormone therapy alone group (figure 2).

\subsection{Pregnancy rate}

No heterogeneity was observed among the 11 studies reporting pregnancy rate $(P=1.00,12=0 \%)$. Meta-analysis with the fixed effects model showed the following: $\mathrm{MD}=2.43,95 \% \mathrm{Cl}[1.84,3.21], \mathrm{Z}=6.23, \mathrm{P}<0.0001$. The statistically significant difference between the two groups suggested that the compound Xuanju capsule + hormone therapy group had a higher pregnancy rate than the hormone therapy alone group (figure 3).

\subsection{LH level}

Heterogeneity was observed among the 12 studies reporting LH levels $(P<0.00001, R=91 \%)$. Meta-analysis with the random effects model showed the following: $\mathrm{MD}=-2.47,95 \% \mathrm{Cl}[-3.07,-1.86], \mathrm{Z}=8.02, P<0.00001$. The statistically significant difference between the two groups suggested that the compound Xuanju capsule + hormone therapy group had a lower LH level than the hormone therapy alone group (figure 4).

Sensitivity analysis: The heterogeneity decreased significantly after excluding the article by Juanjuan Zhang, suggesting that this study may have been the main source of heterogeneity.

\subsection{FSH level}

Heterogeneity was observed among the 12 studies reporting FSH levels. Meta-analysis with the random effects model showed the following: $\mathrm{MD}=0.91,95 \% \mathrm{Cl}[0.32,1.49], \mathrm{Z}=3.04, P=0.002$. The statistically significant difference between the two groups suggested that the compound Xuanju capsule + hormone therapy group had a higher FSH level than the hormone therapy alone group (figure 5).

Sensitivity analysis: The heterogeneity decreased significantly after excluding the studies by Haiyan Wang and Juanjuan Zhang, suggesting these papers may have been the main source of heterogeneity.

\section{7 $\mathrm{E}_{2}$ level}


Heterogeneity was observed among the 7 studies reporting $E_{2}$ levels. Meta-analysis with the random effects model showed the following: $\mathrm{MD}=15.78,95 \% \mathrm{Cl}[7.96,23.60], \mathrm{Z}=3.95, P<0.0001$. The statistically significant difference between the two groups suggested that the compound Xuanju capsule + hormone therapy group had a higher $\mathrm{E}_{2}$ level than the hormone therapy alone group (figure 6 ).

Sensitivity analysis: The heterogeneity decreased significantly after excluding the paper by Xianrong Yu, suggesting that this study may have been the main source of heterogeneity.

\subsection{LH/FSH ratio}

Heterogeneity was observed among the 2 studies reporting the LH/FSH ratio. Meta-analysis with the random effects model showed the following: $\mathrm{MD}=-0.45,95 \% \mathrm{Cl}[-0.67,-0.22], \mathrm{Z}=3.91, \mathrm{P}<0.0001$. The statistically significant difference between the two groups suggested that the compound Xuanju capsule + hormone therapy group had a lower LH/FSH ratio than the hormone therapy alone group (figure 7).

\subsection{T level}

Heterogeneity was observed among the 9 studies reporting $T$ levels. Meta-analysis with the random effects model showed the following: $\mathrm{MD}=-0.36,95 \% \mathrm{Cl}[-0.52,-0.20], Z=4.31, P<0.0001$. The statistically significant difference between the two groups suggested that the compound Xuanju capsule + hormone therapy group had a lower T level than the hormone therapy alone group (figure 8).

Sensitivity analysis: The heterogeneity decreased significantly after excluding the article by Juanjuan Zhang, suggesting that this study may have been the main source of heterogeneity.

\subsection{Endometrial thickness}

Heterogeneity was observed among the 5 studies reporting endometrial thickness. Meta-analysis with the random effects model showed the following: $\mathrm{MD}=-0.36,95 \% \mathrm{Cl}[-0.52,-0.20], \mathrm{Z}=4.31, P<0.0001$. The statistically significant difference between the two groups suggested that the compound Xuanju capsule + hormone therapy group had a lower T level than the hormone therapy alone group (figure 9 ).

Sensitivity analysis: The heterogeneity decreased significantly after excluding the article by Lina Hao, suggesting that this study may have been the main source of heterogeneity.

\subsection{Overall rate of effective treatment}

There were 6 studies reporting the overall rate of effective treatment. Meta-analysis with the fixed effects model showed the following: $\mathrm{OR}=5.35,95 \% \mathrm{Cl}[3.22,8.89], \mathrm{Z}=6.47, P<0.0001$. The statistically significant difference between the two groups suggested that the compound Xuanju capsule + hormone therapy group had a higher overall rate of effective treatment than the hormone therapy alone group (figure 10).

\subsection{Overall rate of effective Chinese medicine-based treatment}

There were 2 studies reporting the overall rate of effective Chinese medicine-based treatment. Meta-analysis with the fixed effects model showed the following: $\mathrm{OR}=4.73,95 \% \mathrm{Cl}[2.00,11.19], \mathrm{Z}=3.53, P=0.0004$. The statistically significant difference between the two groups suggested that the compound Xuanju capsule + hormone therapy group had a higher overall rate of effective Chinese Medicine-based treatment than the hormone therapy alone group (figure 11).

\subsection{BBT}

There were 2 studies reporting BBT. Meta-analysis with the fixed effects model showed the following: OR=2.65, 95\% CI [1.53, 4.57], $Z=3.50, P=0.0005$. The statistically significant difference between the two groups suggested that the compound Xuanju capsule + hormone therapy group had a higher biphasic BBT than the hormone therapy alone group (figure 12).

\subsection{Antral follicle count}

There were 2 studies reporting left antral follicle count. Meta-analysis with the fixed effects model showed the following: MD=-1.13, $95 \%$ $\mathrm{Cl}[-1.85,-0.42], \mathrm{Z}=3.09, P=0.002$. The statistically significant difference between the two groups suggested that the compound $\mathrm{Xuanju}$ capsule + hormone therapy group had a lower left antral follicle count than the hormone therapy alone group (figure 13).

Moreover, there were 2 other studies reporting right antral follicle count.Meta-analysis with the fixed effects model showed the following: $\mathrm{MD}=-1.36,95 \% \mathrm{Cl}[-2.00,-0.72], \mathrm{Z}=4.15, P<0.0001$. The statistically significant difference between the two groups suggested that the 
compound Xuanju capsule + hormone therapy group had a lowerright antral follicle count than the hormone therapy alone group (figure 14).

\subsection{Ovarian volume}

There were 2 studies reporting left ovarian volume. Meta-analysis with the fixed effects model showed the following: $\mathrm{MD}=-0.96,95 \% \mathrm{Cl}$ $[-1.20,-0.72], Z=7.91, P<0.00001$. The statistically significant difference between the two groups suggested that the compound $X u a n j u$ capsule + hormone therapy group had a lower left ovarian volume than the hormone therapy alone group (figure 15).

There were 2 studies reporting right ovarian volume. Meta-analysis with the fixed effects model showed the following: $\mathrm{MD}=-1.09,95 \% \mathrm{Cl}$ $[-1.34,-0.85], Z=8.73, P<0.00001$. The statistically significant difference between the two groups suggested that the compound $X u a n j u$ capsule + hormone therapy group had a lower right ovarian volume than the hormone therapy alone group (figure 16).

\subsection{Follicle count}

There were 2 studies reporting follicle count. Meta-analysis with the fixed effects model showed the following: $\mathrm{MD}=-1.23,95 \% \mathrm{Cl}[-1.56$, -0.89], $Z=7.13, P<0.00001$. The statistically significant difference between the two groups suggested that the compound Xuanju capsule + hormone therapy group had a lower follicle count than the hormone therapy alone group (figure 17).

\subsection{Maximum follicle diameter}

Heterogeneity was observed among the 2 studies reporting maximum follicle diameter. Meta-analysis with the random effects model showed the following: $\mathrm{MD}=2.52,95 \% \mathrm{Cl}[0.68,4.73], \mathrm{Z}=2.68, P=0.007$. The statistically significant difference between the two groups suggested that the compound Xuanju capsule + hormone therapy group had a largermaximum follicle diameterthan the hormone therapy alone group (figure 18).

Figure 18 Comparison of maximum follicle diameter

\subsection{HGF level}

Heterogeneity was observed among the 2 studies reporting HGF levels. Meta-analysis with the random effects model showed the following: $\mathrm{MD}=-85.40,95 \% \mathrm{Cl}[-104.97,-65.82], \mathrm{Z}=8.55, P<0.00001$. The statistically significant difference between the two groups suggested that the compound Xuanju capsule + hormone therapy group had a lower HGF level than the hormone therapy alone group (figure 19).

\subsection{VEGF level}

There were 2 studies reporting VEGF levels. Meta-analysis with the fixed effects model showed the following: MD=-18.46, 95\% CI [-22.43, -14.49], $Z=9.11, P<0.00001$. The statistically significant difference between the two groups suggested that the compound Xuanju capsule + hormone therapy group had a lower VEGF level than the hormone therapy alone group (figure 19).

\subsection{Safety and publication bias}

Adverse effects were reported in only 2 studies, and the descriptions were not detailed. Hence, we were unable to perform a safety evaluation. We performed an inverted funnel plot analysis of the reciprocal of the OR standard errors for ovulation and pregnancy rates; $\mathrm{LH}, \mathrm{FSH}, \mathrm{T}$, and $\mathrm{E}_{2}$ levels; endometrial thickness; and overall rate of effective treatment. We found asymmetric distributions, suggesting that the studies had a small sample size and possible publication bias. The plots are displayed in Figure 20-27.

\section{Discussion}

The results of our study showed that the combination of compound Xuanju capsules and hormone therapy was more effective than hormone therapy alone in improving $\mathrm{LH}, \mathrm{FSH}$, and $\mathrm{E}_{2}$ levels; the overall rate of effective treatment; Kupperman score; ovulation rate; pregnancy rate; LH/FSH ratio; T levels; endometrial thickness; overall rate of effective Chinese medicine-based treatment; BBT; ovarian volume; maximum follicle diameter; follicle count; and HGF and VEGF levels in patients with PCOS-related infertility.

Page $7 / 21$ 
PCOS is the main cause of ovulatory disorder-related infertility in women of reproductive age. PCOS causes hyperandrogenism, polycystic changes in the ovaries, obesity, and hirsutism and eventually leads to infertility, leading to high physiological and psychological burden and affecting quality of life. Western allopathy-based hormone therapy - which relies on $E_{2}$, progesterone, clomiphene, letrozole, tamoxifen, and tripurelin - is the most common method for treating PCOS-related infertility. Such treatment can improve sex hormone levels, promote ovulation, and regularize the menstrual cycle. However, hormone therapy also has several side effects, such as cervical mucosal thickening, luteal insufficiency, luteinized unruptured follicle syndrome, and endometrial thinning. Moreover, it also shows low efficacy in improving clinical symptoms.

Compound Xuanju capsules are mainly composed of Formica fusca L., Epimedium brevicornu, Fructus cnidii, and Fructus lycii. Monarch Formica fusca L. ants are sour, salty, and warm and can promote healthy energy, nourish the blood, and induce Yang Qi, thereby promoting ovulation. Epimedium brevicornu and Fructus cnidii can warm the kidney and invigorate Yang energy, as well as dispel wind and dampness. Among them, Epimedium brevicornu exhibits a hormone-like effect and can increase the weight of reproductive organs in animals. Fructus lycii can have good effects on the kidneys and negate emptiness, draw Yang from Yin, and prevent the aforementioned disadvantages. Studies have suggested that compound Xuanju capsules are effective in warming the kidneys and uterus. Therefore, the use of compound Xuanju capsules along with hormone therapy provides combinatorial benefits and creates a more harmonious environment in the female reproductive system.

In the present study, methodological quality assessment showed that most included studies were of low quality, with methodological issues related to randomization, blinding, and follow-up. Such issues can lead to bias and affect the accuracy and reliability of the studies. Fourteen studies were included in this meta-analysis, and although all reports mentioned the use of randomization, only eight described the specific method (e.g., randomization using a random number table). Concealment was not mentioned in most studies, and details of blinding, loss to follow-up, and withdrawal were not specifically provided, affecting the strength of the evidence provided by the studies. In most studies, the measures of efficacy were the ovulation and pregnancy rates; LH, FSH, T, and $E_{2}$ levels; endometrial thickness; and overall rate of effective treatment. In contrast, few studies focused on the overall rate of effective Chinese medicine-based treatment, BBT, ovarian volume, maximum follicle diameter, follicle count, and HGF and VEGF levels. Future RCTs should not only be designed in a more systematic and robust manner but should also include large sample sizes, strict randomization protocols, and a double-blind approach.

In summary, our meta-analysis showed that the combination of compound Xuanju capsules and hormone therapy is more effective than hormone therapy alone in treating PCOS-related infertility. However, these findings require validation via more rigorous double-blind RCTs with a large sample size. Such validation could increase the credibility of the results and provide more reliable evidence supporting the use of compound Xuanju capsules in combination with hormone therapy for treating PCOS-related infertility.

\section{Abbreviations}

PCOS, polycystic ovary syndrome; LH, luteinizing hormone; FSH, follicle-stimulating hormone; $\mathrm{E}_{2}$, estradiol; T, testosterone; BBT, basal body temperature; HGF, hepatocyte growth factor; VEGF, vascular endothelial growth factor; OR, odds ratios; $\mathrm{Cl}$, confidence interval; $\mathrm{MD}$, mean difference

\section{Declarations}

\section{Ethics approval and consent to participate}

All experimental protocols involving animals were approved by the Ethics Committee of Zhenjiang Hospital of Traditional Chinese Medicine (Zhenjiang, China).

\section{Consent to publish}

All authors consent to publish this article.

\section{Availability of data and materials}

The analyzed datasets generated during the study are available from the corresponding author on reasonable request.

\section{Competing interests}


The authors declare that they have no conflict of interest.

\section{Ethical Statement}

Not applicable.

\section{Fundings}

This research was supported by Natural Science Foundation of China (No. 81873333) and Zhenjiang Social Development of Key Research Project (No.SH2021025).

\section{Authors' Contributions}

MQW conceived and designed research. MQW extracted the data according to the inclusion criteria. MQW and TY analyzed data. MQW and TY wrote the manuscript. All authors read and approved the manuscript.

\section{Acknowledgments}

Not applicable.

\section{References}

[1] Mohamed, Shengir S, Krishnamurthy P, et al. Prevalence and predictors of nonalcoholic fatty liver disease in South Asian women with polycystic ovary syndrome[J]. World Journal of Gastroenterology, 2020, 26(44):142-156.

[2] Gao Z, Ma X, Liu J, et al. Troxerutin protects against DHT-induced polycystic ovary syndrome in rats[J]. Journal of Ovarian Research, 2020, 13(1):106.

[3] ML Sánchez-Ferrer, Adoamnei E , MT Prieto-Sánchez, et al. Health-related quality of life in women with polycystic ovary syndrome attending to a tertiary hospital in Southeastern Spain: a case-control study[J]. Health and quality of life outcomes, 2020, $18(1): 232$.

[4] Ashraf S , Rasool S , Nabi M , et al. Impact of rs2414096 polymorphism of CYP19 gene on susceptibility of polycystic ovary syndrome and hyperandrogenism in Kashmiri women[J]. Scientific Reports, 2021, 11(1):12942.

[5] Yang Z, Zhou W, Zhou C, et al. Steroid metabolome profiling of follicular fluid in normo- and hyperandrogenic women with polycystic ovary syndrome[J]. The Journal of Steroid Biochemistry and Molecular Biology, 2020, 206:105806.

[6] Ignatov A, Ortmann O. Endocrine Risk Factors of Endometrial Cancer: Polycystic Ovary Syndrome, Oral Contraceptives, Infertility, Tamoxifen[J]. Cancers, 2020, 12(7):1766.

[7] Messinis I E , Messini C I , Dafopoulos K. Obesity in polycystic ovary syndrome and infertility[J]. Obesity and Gynecology (Second Edition), 2020:23-34.

[8] Diamond M P , Legro R S , Coutifaris C, et al. Sexual Function in Infertile Women with Polycystic Ovary Syndrome and Unexplained Infertility[J]. American Journal of Obstetrics and Gynecology, 2017:S000293781730563X.

[9] Akpata C B , Uadia P O , Okonofua F E . Prevalence of Polycystic Ovary Syndrome in Nigerian Women with Infertility: A Prospective Study of the Three Assessment Criteria[J]. Open Journal of Obstetrics and Gynecology, 2018, 8(12):1109-1120.

[10] Morgante G , Massaro M G , Di Sabatino A, et al. Therapeutic approach for metabolic disorders and infertility in women with PCOS[J]. Gynecological Endocrinology, 2017:1-6.

[11] The Cochrane Collaboration $₫$ Cochrane Handbook for Systematic Reviews of Interventions Version 5.1.0 [EB/OL]. [2011-03] www.cochrane.org /training /cochrane-handbook.

[12] Cai Dandan. Effect of combined drugs on infertility caused by polycystic ovary syndrome[J]. Chinese Journal of Urban and Rural Industrial Hygiene, 2019, 34(2):85-86. 
[13] Wang Haiyan, Pan Jianshu. Clinical study on 21 cases of infertility with kidney Yang deficiency induced by polycystic ovary syndrome treated with integrated traditional Chinese and Western Medicine[J]. Jiangsu Journal of Traditional Chinese Medicine, 2016, 48(12):30-32.

[14] Yu Xianrong, Hong Xiaoqin. Effects of compound Xuanju capsules combined with progesterone and clomiphene on sex hormone level and pregnancy in patients with PCOS infertility[J]. Medical Innovation of China, 2021, 18(19):83-86.

[15] Sun Jinlong, Lian Fang, Sun Zhengao. Clinical observation of compound Xuanju capsules combined with letrozole in the treatment of 45 cases of infertility with polycystic ovary syndrome of kidney Yang deficiency[C]. Proceedings of the 9th National Symposium on Gynecology of traditional Chinese medicine, 2009:579-682.

[16] Zhang Juanjuan, Zhang Chunlian, Wang Chaoyun, et al. Progesterone combined with compound Xuanju capsules in the treatment of infertility caused by polycystic ovary syndrome[J]. The Chinese Journal of Human Sexuality, 2017, 26(8):121-123.

[17] Huang Xiaohong. Clinical observation of compound Xuanju capsules combined with clomiphene in the treatment of infertility with polycystic ovary syndrome[J]. Maternal and child health care of China, 2012, 27(33):5426-5428.

[18] Li Gang. Clinical study of compound Xuanju capsules combined with triptorelin in the treatment of infertility with polycystic ovary syndrome[J]. Chinese Journal of Modern Drug Application, 2020, 14(4):11-13.

[19] Hu Yunfang, Huang Yi, Li Liuming. Effect of compound Xuanju capsule, clomiphene and estradiol valerate on polycystic ovary syndrome complicated with infertility (kidney Yang deficiency type)[J]. Maternal and child health care of China, 2017, 32(12):2705-2708.

[20] Hao Lina, Xia Tinge. Clinical efficacy of compound Xuanju capsules combined with letrozole in the treatment of infertility with polycystic ovary syndrome[J]. Clinical Medical Research and Practice, 2018, 3(32):144-145.

[21] Chen Zhifang, Shen Jufeng, Shi Genmei. Progesterone combined with compound Xuanju capsules in the treatment of infertility with polycystic ovary syndrome and its effect on ovarian function[J]. Chinese Journal of Family Planning, 2019, 27(2):72-75.

[22] Yan Li. Effect of compound Xuanju capsules combined with tamoxifen on sex hormone level and pregnancy rate in infertile patients with polycystic ovary syndrome[J]. China's Naturopathy, 2019, 27(4):77-79.

[23] Ge Bingbing. Clinical effect of compound Xuanju capsules combined with clomiphene and progesterone Capsule on infertility patients with polycystic ovary syndrome[J]. Henan Medical Research, 2021, 30(8):1499-1501.

[24] Zhou Qingmin. Effect of compound Xuanju capsules combined with tamoxifen on infertility patients with polycystic ovary syndrome[J]. Henan Medical Research, 2020, 29(4):688-689.

[25] Li Yingying. Effect of compound Xuanju capsules combined with ethinylestradiol and cyproterone tablets on infertility patients with polycystic ovary syndrome[J]. Medical Journal of Chinese People's Health, 2021, 33(13):67-69.

\section{Figures}


Searching by computer $(\mathrm{n}=572)$, including CNKI: 262, Wan Fang: 56, WEI PU: 253, Pubmed: 1 , Web of science: 0 , Cochrane library: 0

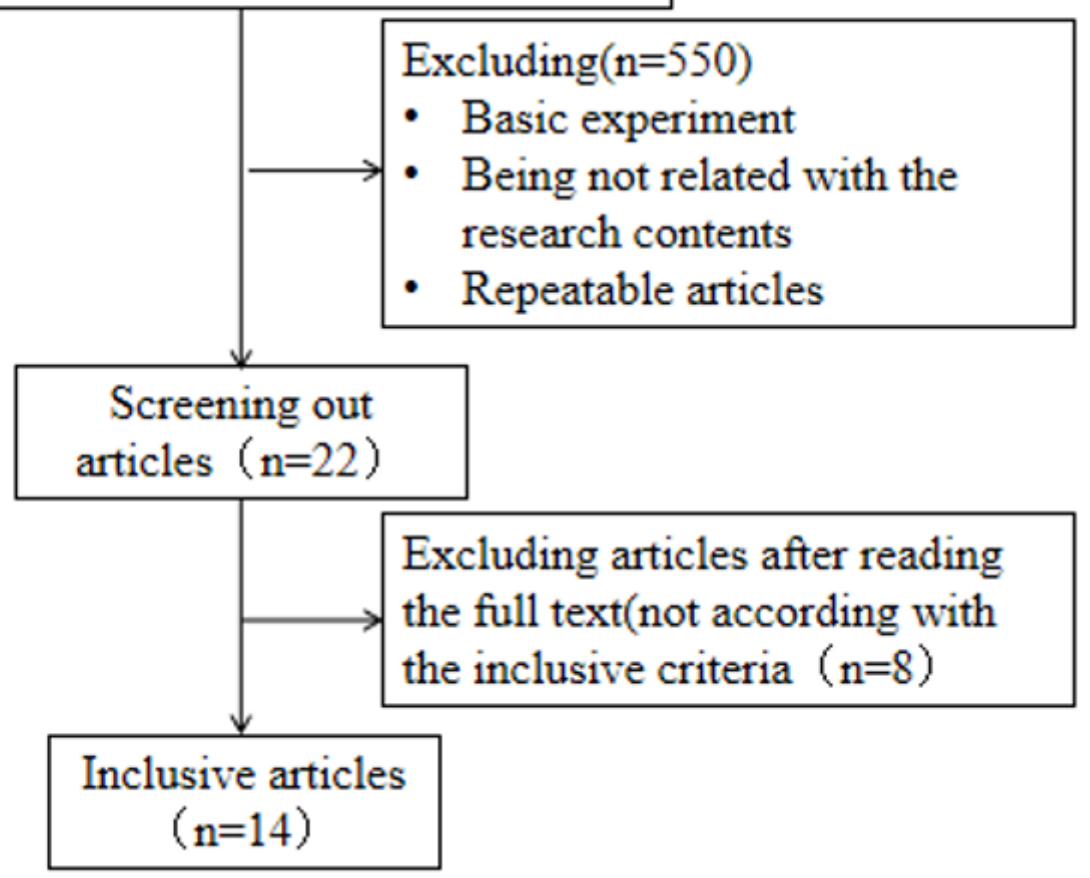

Figure 1

Data screening process



Figure 2

Comparison of ovulation rate 
Experimental Control

Study or Subaroup

Cai DD 2019

Chen ZF 2019

Ge BB 2021

Hu YF 2017

Huang $X \mathrm{H} 2012$

Li YY 2021

Sun JL 2009

Wang HY 2016

Yan L 2019

YUXR 2021

Zhang JJ 2017

Total $(95 \% \mathrm{Cl})$

Total events

Heterogeneity: $\mathrm{Ch}^{2}=1.68, \mathrm{df}=10(\mathrm{P}=1.00) ; \mathrm{I}^{2}=0 \%$

Test for overall effect: $Z=6.23$ ( $P<0.00001$ )
Odds Ratio

$2.71[1.20,6.16]$

$1.64[0.68,3.94]$

$2.29[1.06,4.96]$

$2.86[1.09,7.52]$

$4.26[0.81,22.53]$

$2.88[1.09,7.60]$

$2.35[0.99,5.62]$

$2.17[0.63,7.44]$

$2.51[1.06,5.94]$

$2.59[1.08,6.20]$

$2.11[0.84,5.26]$

$458 \quad 100.0 \% \quad 2.43[1.84,3.21]$





Favours [experimental] Favours [control]

\section{Figure 3}

Comparison of pregnancy rate

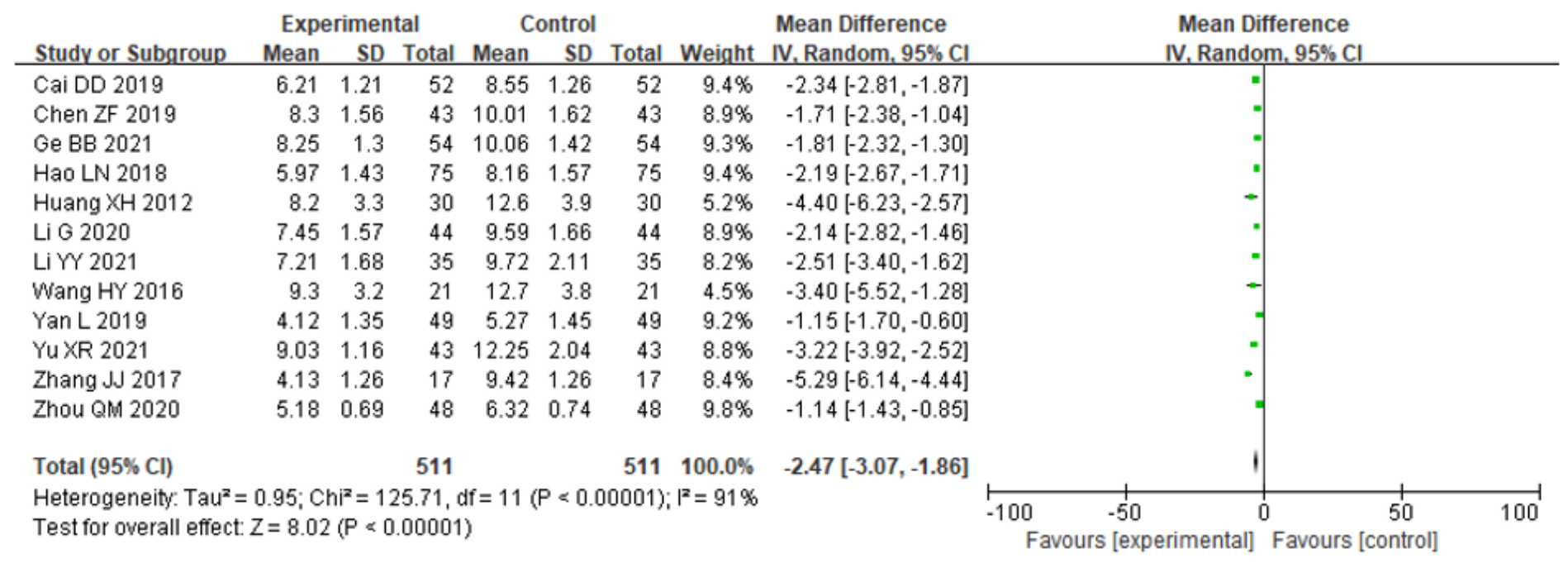

\section{Figure 4}

Comparison of LH level 




\section{Figure 5}

Comparison of FSH level



\section{Figure 6}

Comparison of E2 level



\section{Figure 7}

Comparison of LH/FSH ratio 




\section{Figure 8}

Comparison of T level

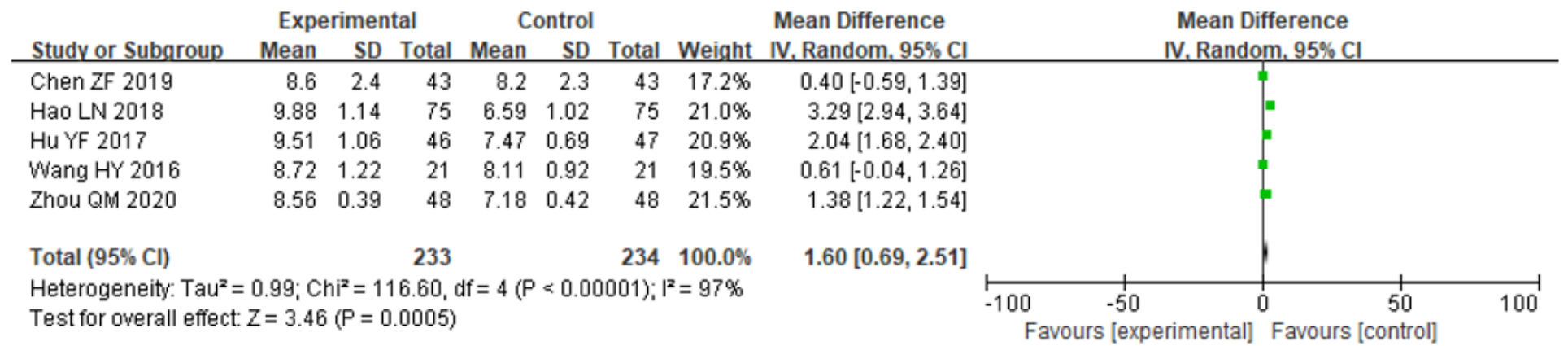

\section{Figure 9}

Comparison of endometrial thickness

Experimental

Study or Subgroup

Chen ZF 2019

Ge BB 2021

Hao LN 2018

Li G 2020

Yan L 2019

Zhou QM 2020

Total $(95 \% \mathrm{Cl})$

Total events

Heterogeneity: Chi $^{2}=3.30, d f=5(P=0.65) ;\left.\right|^{2}=0 \%$

Test for overall effect: $Z=6.47$ ( $P \propto 0.00001)$
Control

Odds Ratio

$\begin{array}{llllll}39 & 43 & 31 & 43 & 19.0 \% & 3.77\end{array}[1.11,12.86]$

$\begin{array}{lllllll}49 & 54 & 41 & 54 & 25.0 \% & 3.11[1.02,9.44]\end{array}$

$\begin{array}{llllll}72 & 75 & 52 & 75 & 13.7 \% & 10.62[3.03,37.23]\end{array}$

$\begin{array}{llllll}42 & 44 & 30 & 44 & 9.0 \% & 9.80[2.07,46.35]\end{array}$

$\begin{array}{llllll}44 & 49 & 34 & 49 & 22.9 \% & 3.88\end{array}[1.28,11.74]$

$\begin{array}{llllll}46 & 48 & 38 & 48 & 10.4 \% & 6.05\end{array}[1.25,29.32]$

$313 \quad 313 \quad 100.0 \% \quad 5.35[3.22,8.89]$

Favours [experimental] Favours [control]

Odds Ratio M-H, Fixed, $95 \% \mathrm{Cl}$



Figure 10

Comparison of overall rate of effective treatment 




Figure 11

Comparison of overall rate of effective Chinese medicine-based treatment



\section{Figure 12}

Comparison of BBT



Figure 13

Comparison of left antral follicle count

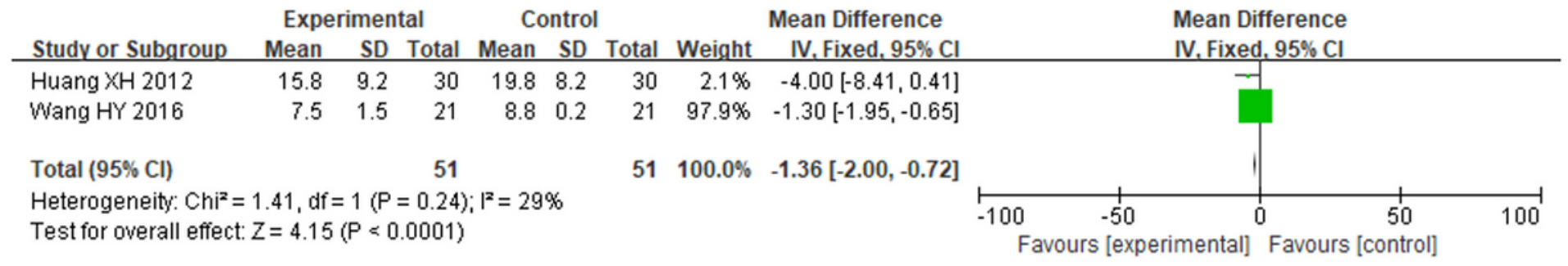

\section{Figure 14}

Comparison of right antral follicle count 




\section{Figure 15}

Comparison of left ovarian volume

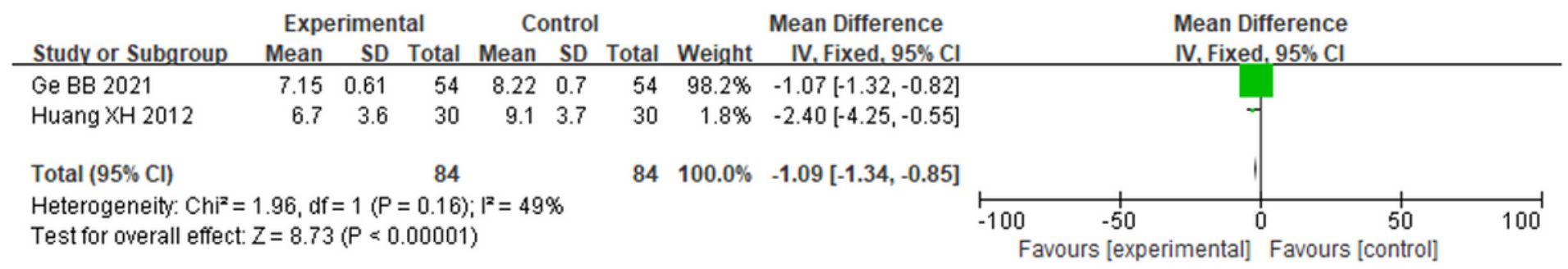

\section{Figure 16}

Comparison of right ovarian volume



Figure 17

Comparison of follicle count



\section{Figure 18}

Comparison of maximum follicle diameter

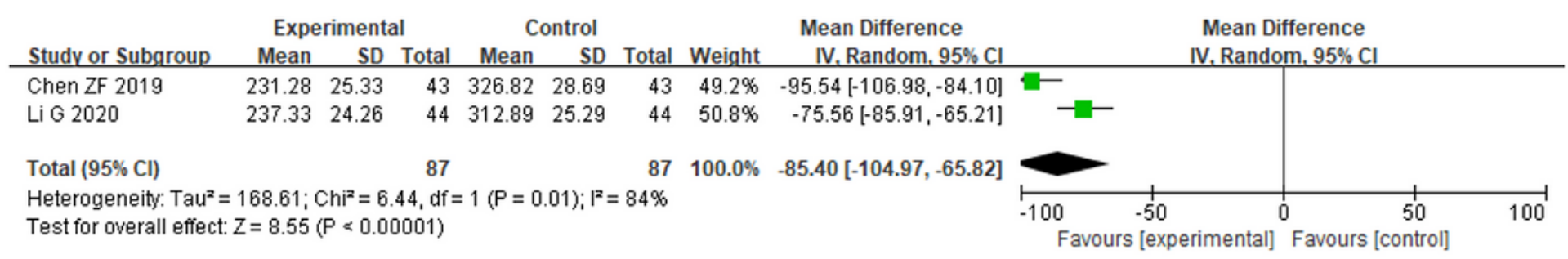




\section{Figure 19}

Comparison of HGF

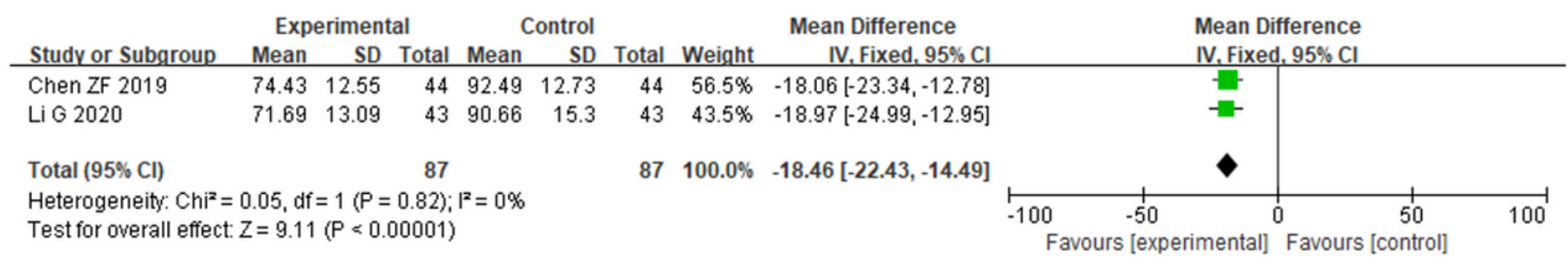

Figure 20

Comparison of VEGF

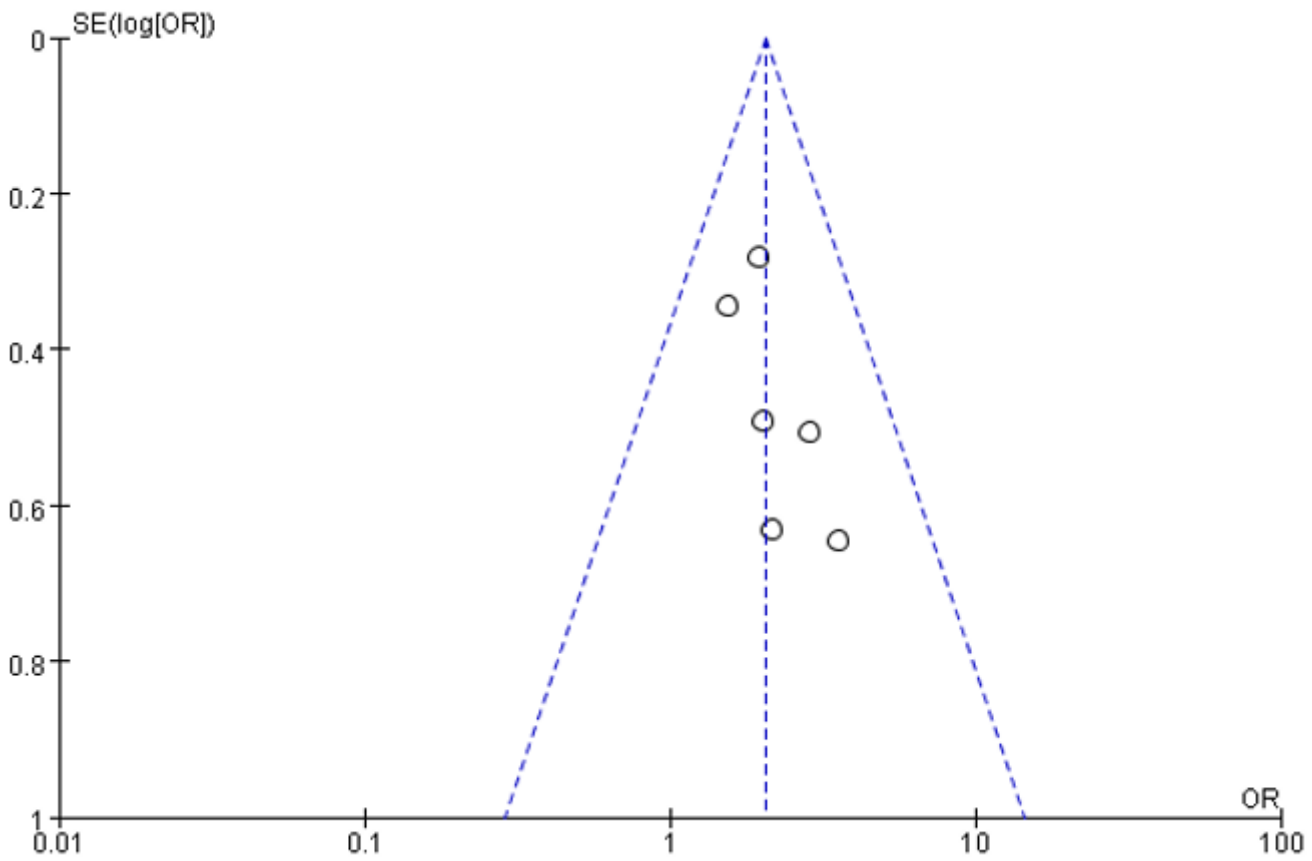

\section{Figure 21}

Funnel plot of ovulation rate 




Figure 22

Funnel plot of pregnancy rate

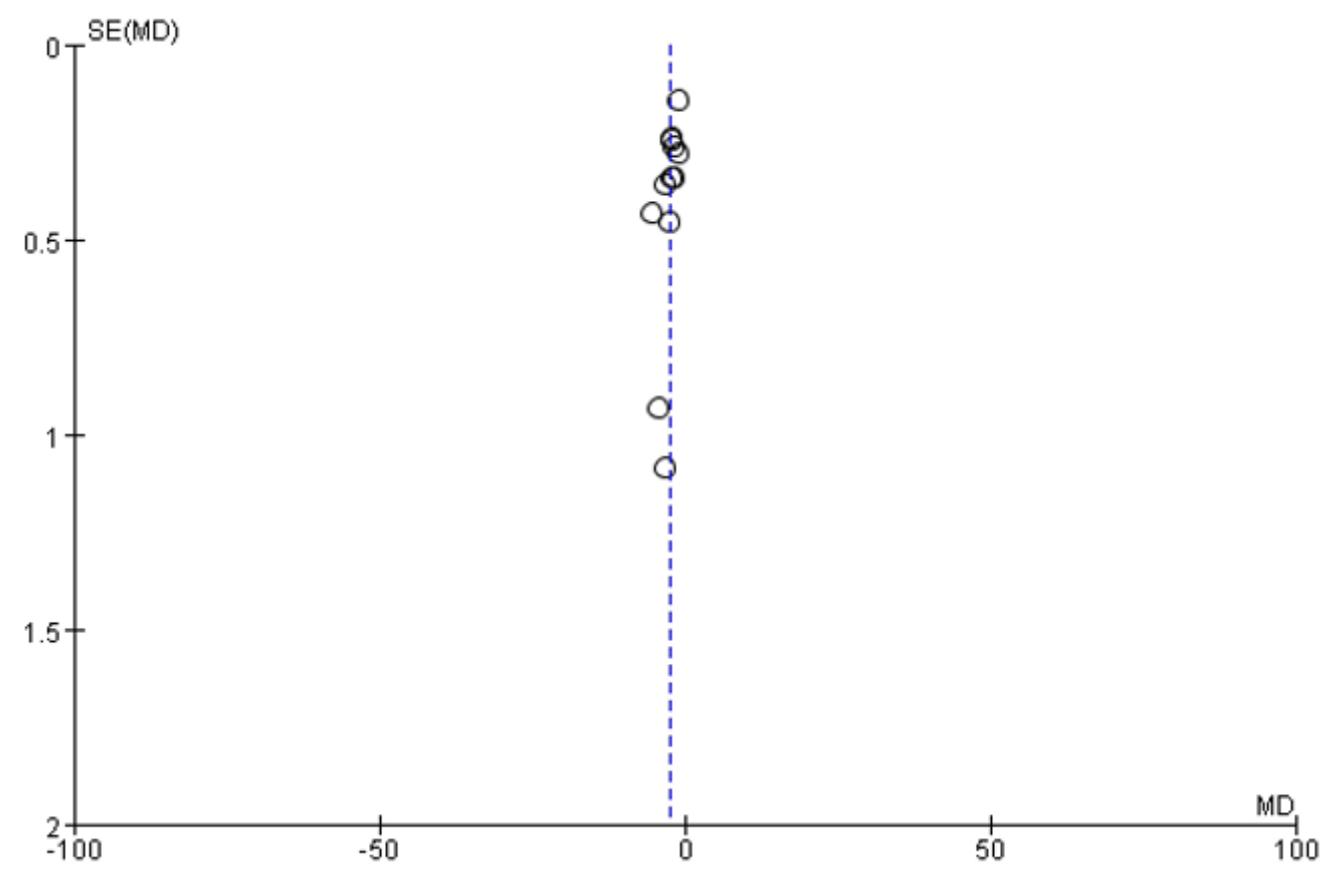

Figure 23

Funnel plot of LH level 


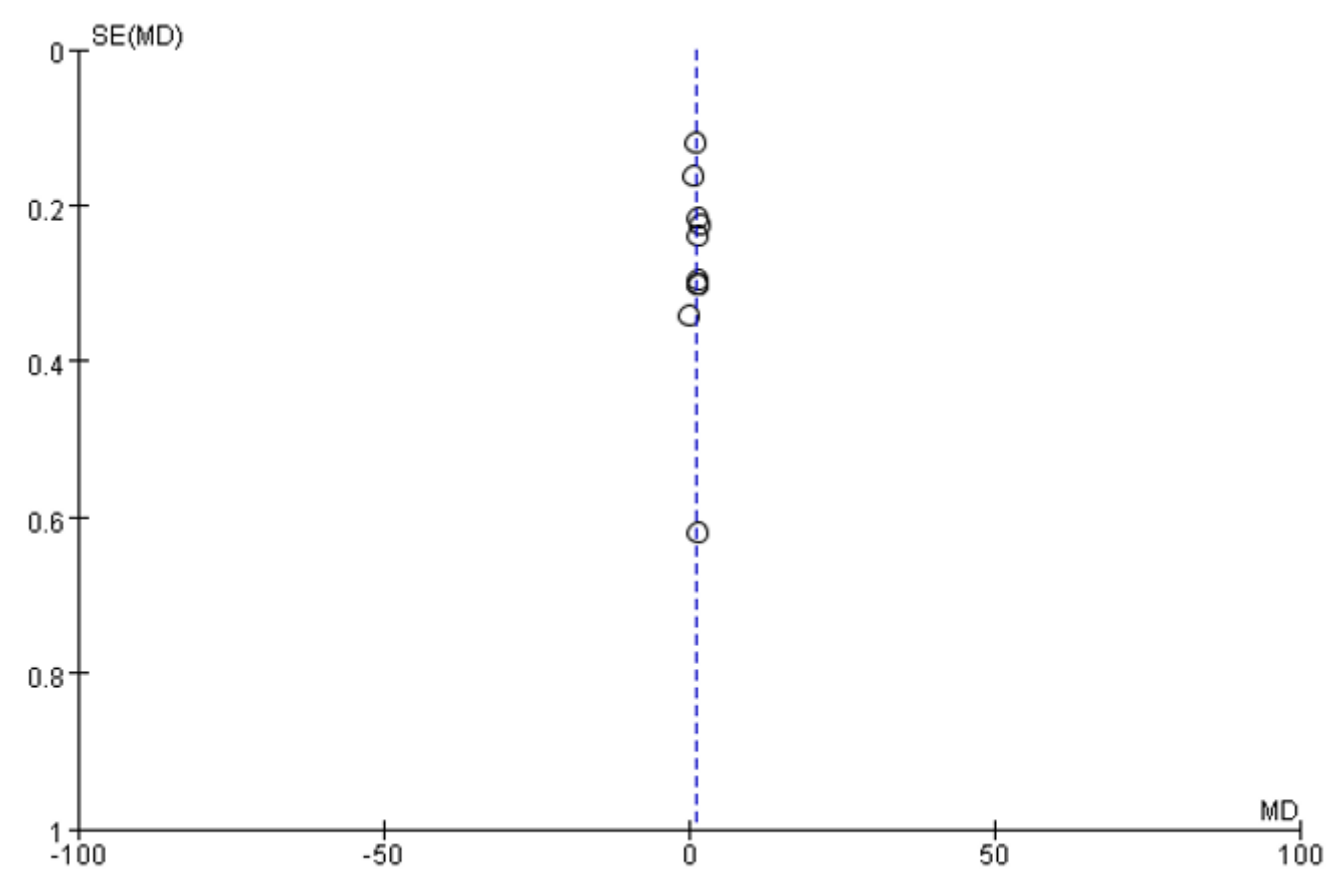

Figure 24

Funnel plot of FSH level

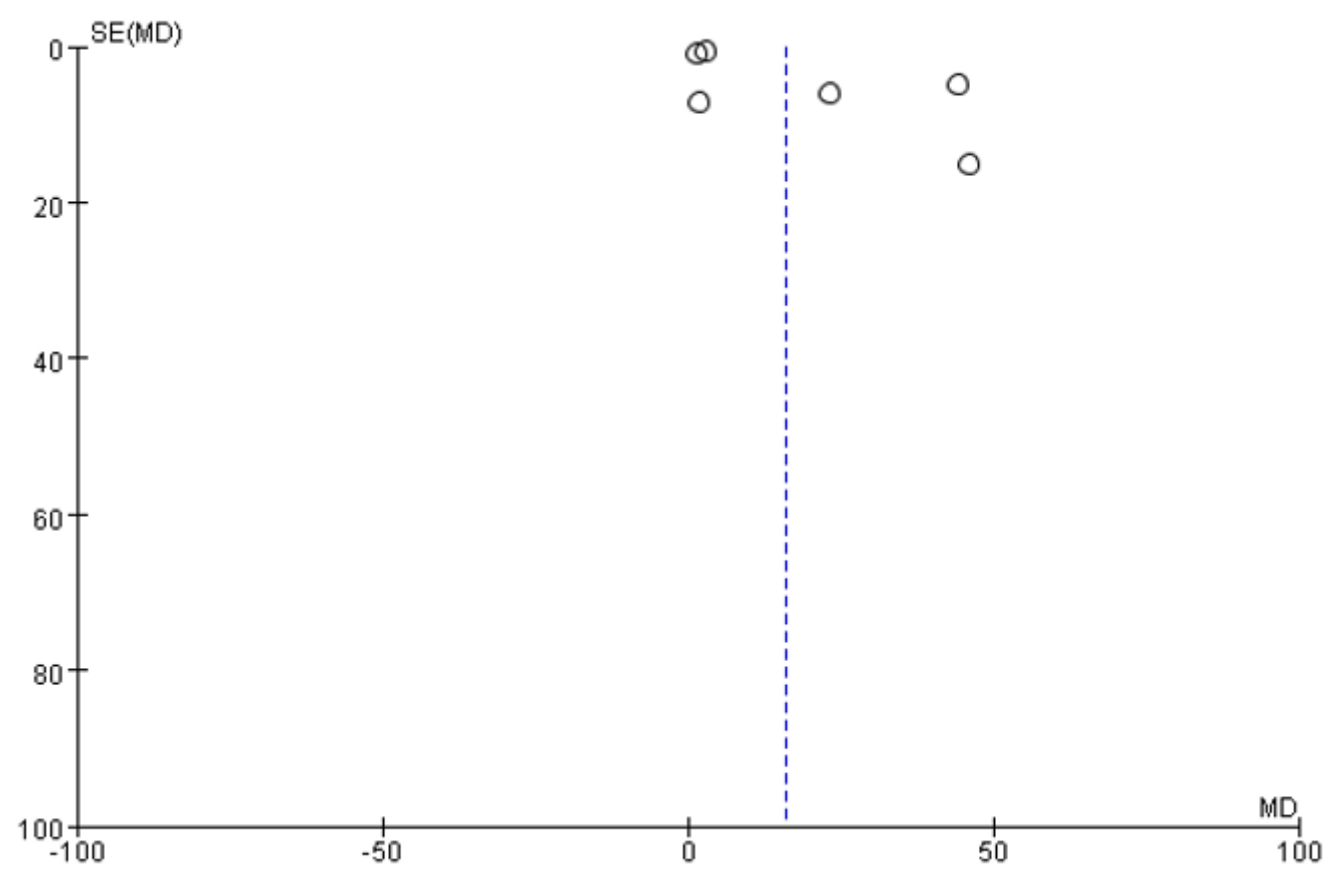

Figure 25

Funnel plot of E2 level 


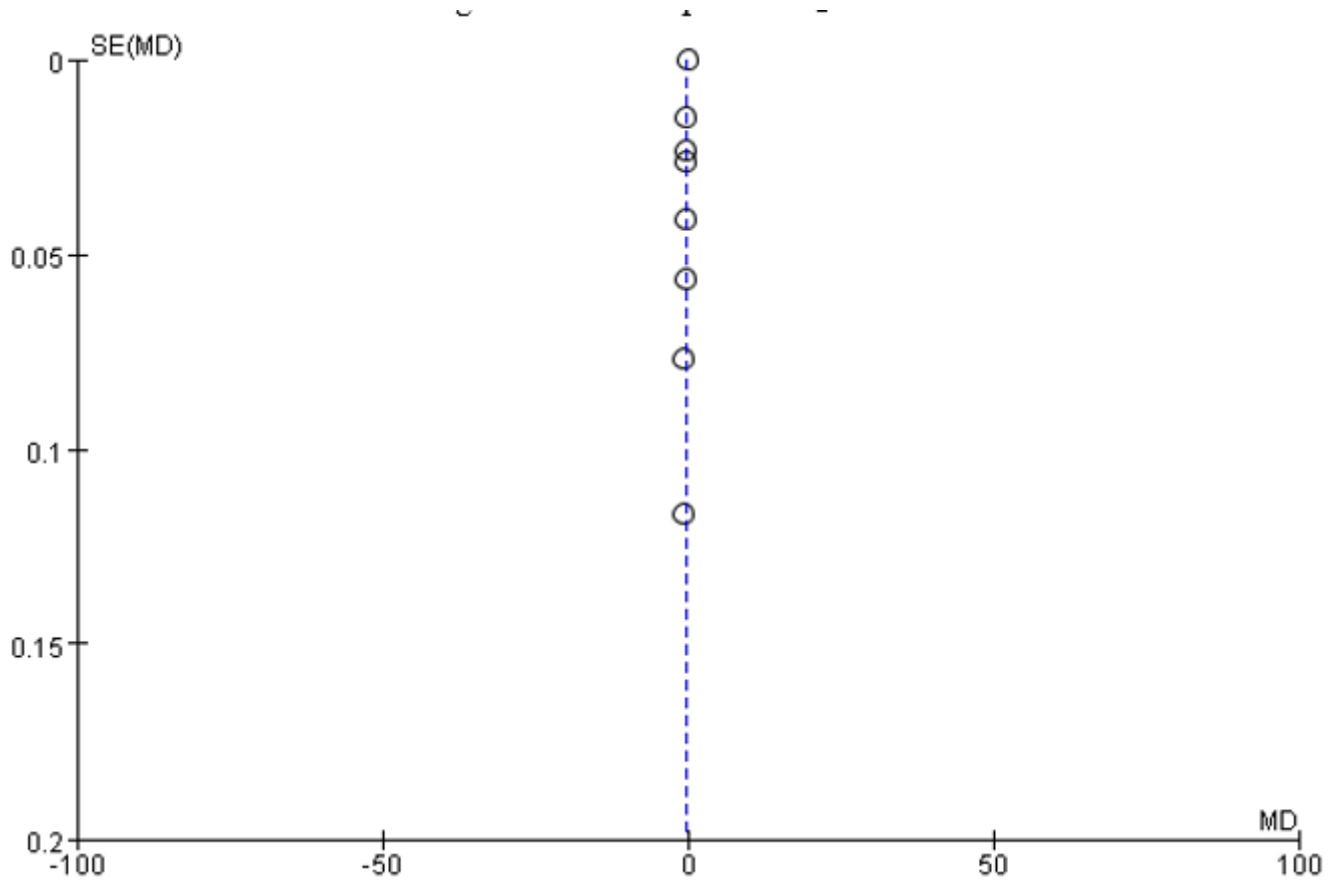

Figure 26

Funnel plot of T level

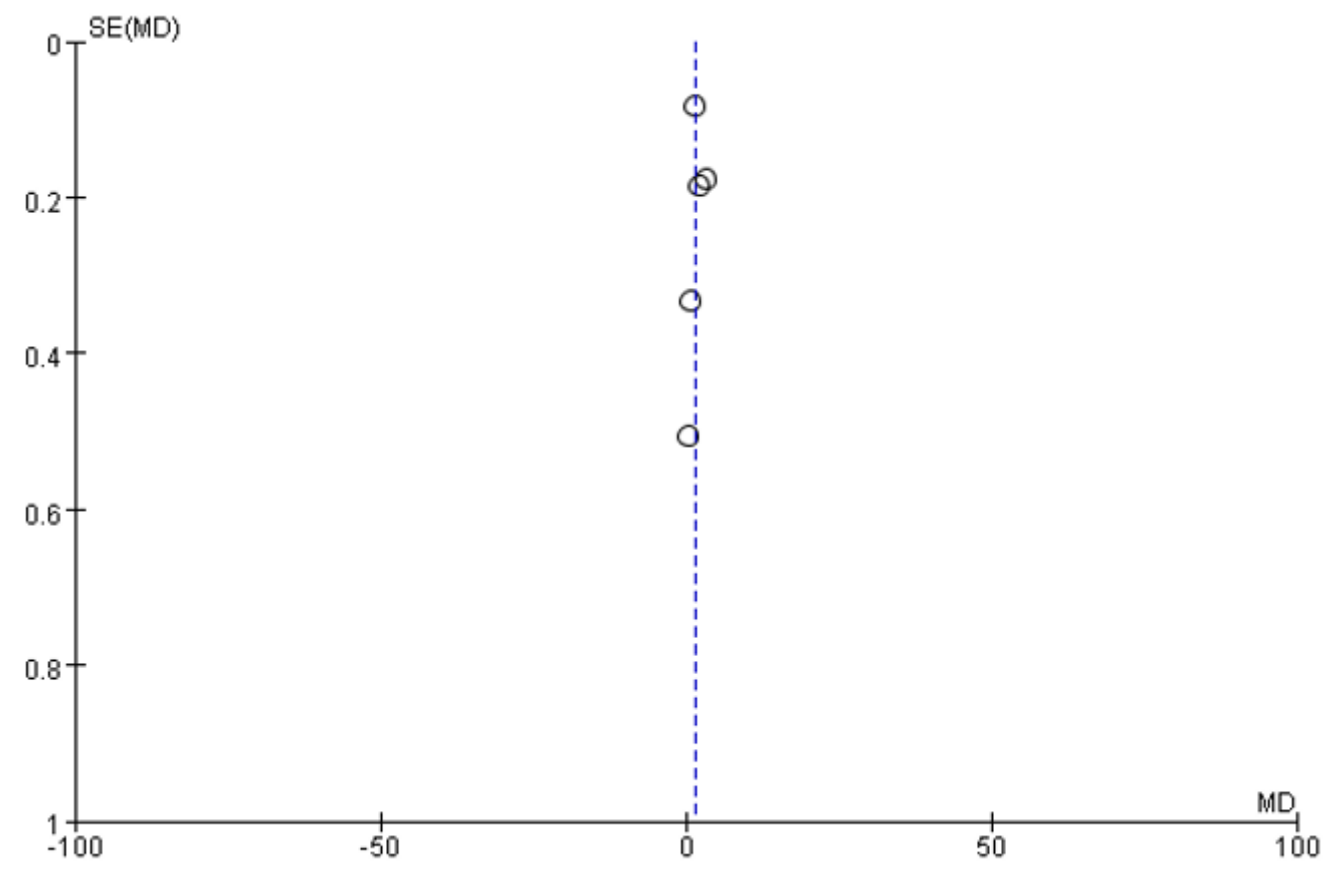

Figure 27

Funnel plot of endometrial thickness 




Figure 28

Funnel plot of overall rate of effective treatment 